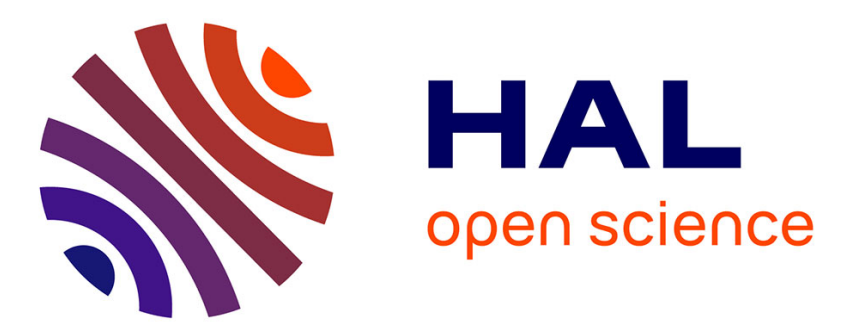

\title{
Bromide-Regulated Anisotropic Growth of Desert-Rose-Like Nanostructured Gold onto Carbon Fiber Electrodes as Freestanding Electrocatalysts
}

Paul Morandi, Nazym Tuleushova, Sophie Tingry, Julien Cambedouzou, Shelley Minteer, David Cornu, Yaovi Holade

\section{To cite this version:}

Paul Morandi, Nazym Tuleushova, Sophie Tingry, Julien Cambedouzou, Shelley Minteer, et al.. Bromide-Regulated Anisotropic Growth of Desert-Rose-Like Nanostructured Gold onto Carbon Fiber Electrodes as Freestanding Electrocatalysts. ACS Applied Energy Materials, 2020, 3 (8), pp.75607571. 10.1021/acsaem.0c01008 . hal-02946333

\section{HAL Id: hal-02946333 \\ https://hal.science/hal-02946333}

Submitted on 23 Nov 2020

HAL is a multi-disciplinary open access archive for the deposit and dissemination of scientific research documents, whether they are published or not. The documents may come from teaching and research institutions in France or abroad, or from public or private research centers.
L'archive ouverte pluridisciplinaire HAL, est destinée au dépôt et à la diffusion de documents scientifiques de niveau recherche, publiés ou non, émanant des établissements d'enseignement et de recherche français ou étrangers, des laboratoires publics ou privés. 


\section{Bromide-Regulated Anisotropic Growth of Desert Rose-like Nanostructured Gold onto Carbon Fiber Electrodes as Free-Standing Electrocatalysts}

Paul Morandi, ${ }^{1}$ Nazym Tuleushova, ${ }^{1}$ Sophie Tingry, ${ }^{1}$ Julien Cambedouzou, ${ }^{1}$ Shelley D. Minteer, ${ }^{2, *}$ David Cornu, ${ }^{1, *}$ and Yaovi Holade ${ }^{1, *}$

${ }^{1}$ Institut Européen des Membranes, IEM UMR 5635, Univ Montpellier, ENSCM, CNRS, 34090 Montpellier, France.

${ }^{2}$ Department of Chemistry, University of Utah, 315 S 1400 E, Room 2020, Salt Lake City, Utah, 84112, USA

ABSTRACT: Three-dimensional (3D) gas diffusion electrodes (GDEs) as support for catalytic nanoparticles are important to the electrolysis and fuel cells fields to facilitate reactant transport and distribution, and reach higher current densities. Hence, the assembly of nanostructured catalytic particles directly onto GDEs during the synthesis could be a powerful one-step strategy to target high performance and long-term durability thanks to the induced strong nanoparticlesupport interaction. We report herein the use of bromide anions to shape the anisotropic growth of nanostructured desert-rose-like gold particles directly onto the GDE, as a freestanding GDEAu catalyst for straightforward use in electrolysis without an additional step. We showed that the bromide ions determine the anisotropy of the particles, resulting in a growth of gold into nanoplates enclosed by (111) facets. The formation of hierarchical nanostructured 3D Au at the GDE surface was explained by the nanoparticle-mediated aggregation mechanism and the preferential adsorption of $\mathrm{Br}^{-}$on the (111) facet leaving behind dominant planar structured nuclei, which then self-assemble. Electrocatalytic tests towards the glycerol electrooxidation demonstrated that the as-synthesized freestanding surfactant- and binder-free GDE-Au material 
$\left(100 \mu \mathrm{g}_{\mathrm{Au}} \mathrm{cm}^{-2}\right)$ delivered a high specific peak current density of $j_{\mathrm{p}}=33 \mathrm{~mA} \mathrm{~cm}_{\mathrm{Au}}{ }^{-2}$, which is 3 and 7 higher than the tested commercial $\mathrm{Au} / \mathrm{C}$ nanocatalyst at loadings of 76 and $152 \mu \mathrm{g}_{\mathrm{Au}} \mathrm{cm}^{-2}$, respectively. This study provides future directions for the synthesis and application of nanostructured catalysts for alcohol oxidation as an alternative to anodic oxygen evolution, which consumes the majority of the electricity input during the electrolysis.

KEYWORDS: anisotropic growth, catalyst, gold, gas-diffusion electrodes, glycerol oxidation

\section{INTRODUCTION}

Gas diffusion electrodes (GDEs) are utilized in electrolysis and fuel cells to overcome mass transport limitations, improve the catalyst utilization efficiency, and increase the current density. ${ }^{1-3}$ A GDE is typically a three-dimensional (3D) material of tens to hundreds of micrometer thickness and made of carbon micro- or nano-fibers, thus constituting a porous electrode with tunable hydrophobicity. The issue is that the most frequently reported strategies for the synthesis of metal nanoparticles as catalysts are based on the reduction of the corresponding metal salts. The result is the production of nanocatalysts in powder or liquid form. Hence, before being used in electrolysis or fuel cells, the collected nanoparticles need to be physically attached to an electrically conductive support, which is the GDE before the integration into a membrane-electrode-assembly type mounting in order to obtain the most compact arrangement. It was reported that the activity generally measured at small electrodes (e.g., glassy carbon electrode) using a typical three-electrode cell is a poor indicator of performance in the solid-state polymer electrolyte membrane system. ${ }^{4}$ The challenge is that a liquid mixture has to be prepared by re-dispersing the collected nanoparticles in the presence of a binder to form a homogeneous catalytic ink. A binder such as Nafion ionomer is required during this immobilizing step to guarantee the stability, which does not simplify the electrode assembly and leads to loss of performance during operation. It should be mentioned that the ionomer also play an important role as an ion conductor within the electrode. Those approaches also lead to the need for a relatively high loading of metals of several hundreds or even thousands of micrograms of metal per square centimeter of the electrode. Given the high price and scarcity of platinum group metals, a significant reduction of the loading is desired., 50 in order to avoid collecting 
and immobilizing high amounts of the nanoparticles after the synthesis, the obvious and convenient solution is the preparation of the active sites directly on the GDE. During the last years, researchers have reported attempts via atomic layer deposition (ALD), ${ }^{7,8}$ electrodeposition, ${ }^{9-11}$ electrospinning, ${ }^{12,13}$ reactive spray deposition, ${ }^{14,15}$ and chemical/hydrothermal ${ }^{16,17}$ processes.

Relatively small organic compounds such as methanol, ethanol, glycerol, and glucose are oxidized at an oxidation potential below $1 \mathrm{~V}$ vs. reversible hydrogen electrode (RHE) at platinum-palladium-gold surfaces. This is significantly lower than that of the oxygen evolution reaction (OER, higher than $1.4 \mathrm{~V}$ vs RHE), so that the oxidation of those organic compounds instead of water at the anode in electrolyzers is expected to significantly lower the input energy. ${ }^{18-21}$ Also, because the anode reaction only occurs in a potential range well below $1 \mathrm{~V}$ vs RHE, carbon fiber papers as support in anode were used in organic-fuelled reactors without concern for their oxidation. ${ }^{18,22}$ This emerging research direction constitutes a meaningful option to advance the development of an efficient anode to be associated with the electricity-driven half-cell processes of hydrogen evolution reaction (HER), $\mathrm{CO}_{2}$ reduction reaction (CO2RR), and $\mathrm{N}_{2}$ reduction reaction (N2RR) for the production of valuable fuels and chemicals. Verma et al. ${ }^{18}$ reported that the anodic electrooxidation of glycerol during CO2RR into ethylene and ethanol can reduce the consumed electricity by up to $53 \%$, thus decreasing the operating costs and the environmental footprint. It should be emphasized that glycerol is a co-product of the industrial manufacturing of biodiesel and soap, where biodiesel produces 10\% wt./wt. of crude glycerol. Indeed, the main motivation of the research during the last years was to find a method that promotes the selective oxidization of glycerol into valuable chemicals instead of the total oxidation into $\mathrm{CO}_{2}$ that will contribute to pollution. So the coupling of a selective oxidation at the anode of an electrolyzer to an electroreduction reaction such as CO2RR at the cathode is expected to significantly reduce the energy consumption and the release in the atmosphere of polluting carbon species, thus the decrease in the costs and the environmental impact. It is even envisaged that if $\mathrm{CO}_{2}$ were the reaction product, it would be sent to the cathode to produce higher value-added chemical intermediates such as ethylene and ethanol. ${ }^{18,23}$ Furthermore, gold is the only element that provides a good balance between catalytic activity, selectivity, and stability for the glycerol oxidation. ${ }^{24-26}$ Its nanostructuration is desired to fabricate cost-effective catalysts by increasing the number of active sites. It is worth mentioning that the reported 
precious metal-free materials to electro-catalyze the oxidation of glycerol need a potential range of 1.4-1.9 V vs RHE in order to get high current densities, as recently reviewed by the group of Baranova. ${ }^{27}$ Given the higher potential, the idea of using an organic compound to lower the potential of the anode apparently violates the initial need of reducing the proportion of energy consumed by the anode, of the order of $90 \%$ in conventional water electrolyzer. ${ }^{18,23}$ Those facts explain why the presence of the three metals $\mathrm{Au}, \mathrm{Pt}$ or Pd, which are the only species giving good activity in low potentials, is practically unavoidable for the development of reliable anodes for the organics oxidation. Thus, the smart solution should be their nano-structuring and/or the combination with other elements $(\mathrm{Bi}, \mathrm{Ni}, \mathrm{Ag}$, etc.) to significantly reduce their quantity while providing a synergistic effect.

To date, various methods were reported to engineer catalytically active $\mathrm{Au}, \mathrm{Pd}$, and $\mathrm{Pt}$ nanoparticles of different shapes, morphologies and sizes for application in heterogeneous surface reactions..$^{9,10,28-30}$ This was mainly facilitated by the use of capping agents such as organic molecules that adsorb on the surface of a crystal to control its size and selectively stabilize certain crystallographic planes by regulating growth in aqueous or organic solutions. This advantage finally turns into a major obstacle when these particles have to be used in electrocatalysis, since it becomes almost impossible to remove completely these organic molecules from the metal surface. The remaining molecules of the surfactant thereby impede access to all catalytically active sites and have the potential to undesirably alter the selectivity of the reaction under investigation. ${ }^{31-33}$ To benefit from the strong nanoparticle-substrate interaction, avoid the use of organic molecule-based organic surfactants or capping agents, and target high electrocatalytic performance, we reported the direct growth of anisotropic gold nanostructures directly onto a GDE support, wherein the key role of halides $\left(\mathrm{I}^{-}, \mathrm{Br}^{-}\right.$, and $\left.\mathrm{Cl}^{-}\right)$ was emphasized. ${ }^{29}$ Enhanced electrocatalytic activity and stability towards the electrooxidation of glucose in a basic solution was observed in a half-cell as well as a record performance in a direct glucose fuel cell with a maximum power density of $3 \mathrm{~mW} \mathrm{~cm}{ }^{-2}$ in unstirred solution. However, in this previous study, the particles were deposited on both sides of the GDE. At the end, our initially developed strategy $y^{29}$ is only applicable for simple use where the electrode is supposed to be dipped in the solution. This is not necessarily optimal for the membraneelectrode-assembly setup, whereby the membrane is sandwiched between an anode and a cathode, both of which being based on GDEs. Therefore, only the side facing the membrane 
should constitute the active phase, i.e. contain the catalytic nanoparticles. Furthermore, for the electrocatalytic glycerol oxidation, much less attention was given to the strategy of direct synthesis of nanoparticles exactly at one face of the GDE. It is thus important to develop a strategy that allows nanostructured particles to grow directly on only one side, which is the purpose of the present study. So, we revisited this method in order to directly put Au particles onto GDE (GDE-Au) without using an organic molecule as a capping agent or surfactant during the synthesis. Hence, a binder such as Nafion ionomer is consequently not needed during the electrochemical measurement. Our results showed that bromide halide triggers the anisotropic growth of desert rose-like nanostructured gold particles on the carbon fibers surface, which leads

to the recovery of $5 \times 5 \mathrm{~cm}^{2}$ electrodes as freestanding electrocatalysts. The comparative electrocatalytic study towards the glycerol oxidation in alkaline media with the commercial Vulcan-supported gold nanoparticles showed that GDE-Au exhibits a higher performance than the reference nanocatalyst.

\section{RESULTS AND DISCUSSION}

\section{Growth of Anisotropic Gold Particles onto GDE Support.}

Suitability of the GDE as a support for the synthesis requires deep physical scrutinizing to assess whether or not the surface of its constituting fibers would be suitable for the growth of gold particles. Specifically, the hydrophobic/hydrophilic character (wettability) is a prerequisite for purposes of bottom-up synthesis and electrocatalysis in aqueous media. In fact, in the case of a repulsing force between the support surface and metallic particles being deposited, it becomes essential to carry out an activation phase that enables obtaining high loading and significant electrocatalysis. Recent analysis by X-ray photoelectron spectroscopy (XPS) revealed the presence of a substantial amount of oxygen species supported by water contact angle measurements, ${ }^{7}$ which means that the GDE is suitable for direct use in aqueous solutions without further pre-treatment stages. Figure la presents a representative scanning electron microscopy (SEM) image of a bare GDE-material. For all SEM analysis, a thin layer (1-5 nm) of platinum was deposited to enhance the imaging capability. Additional low and high-resolution images of 
the GDE are reported in Figure S1. The images show that the GDE is composed of $\sim 7 \mu \mathrm{m}$ microfibers leading to a 3D network made of a stack of 190/7 $=27$ layers.

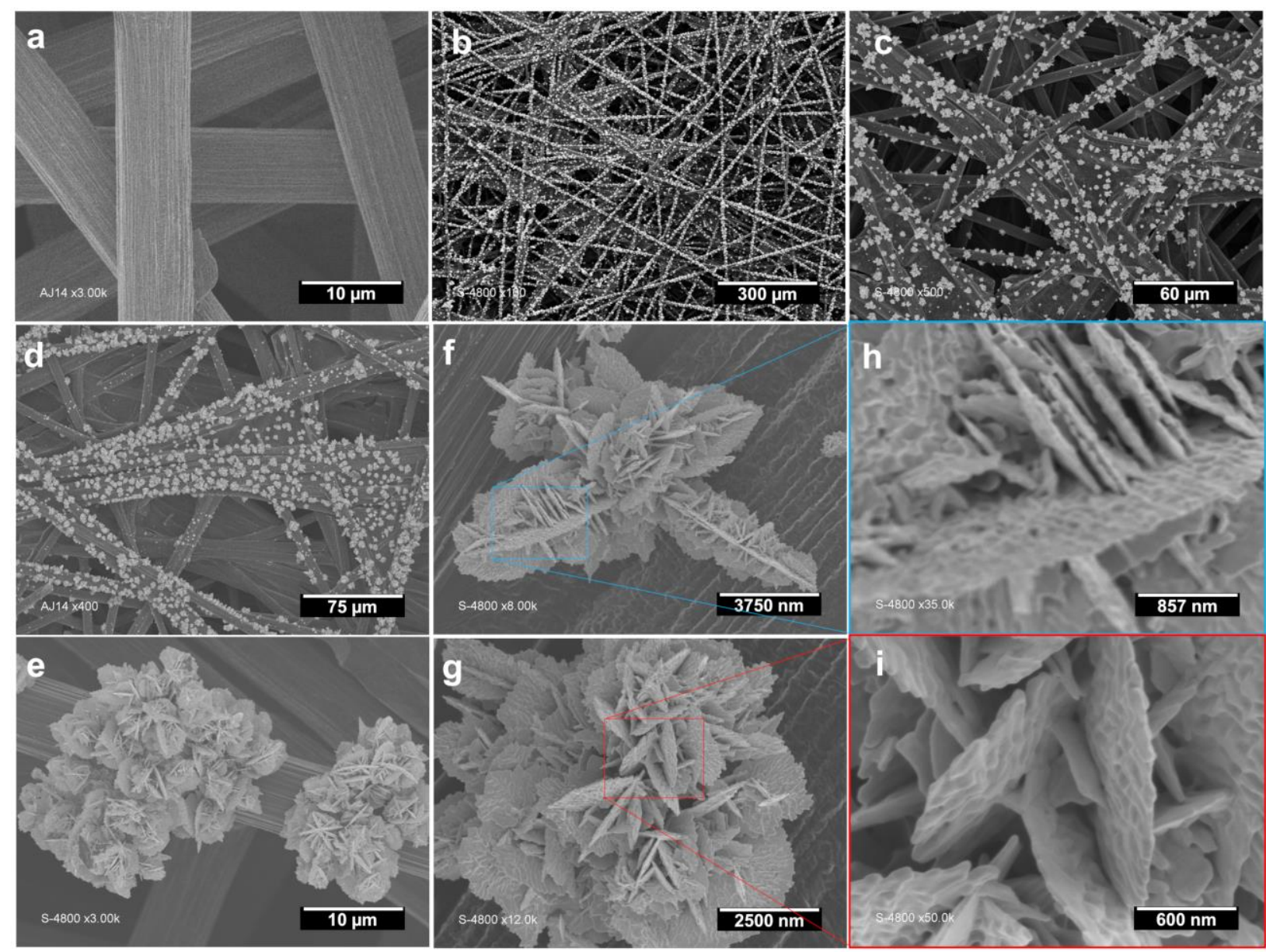

Figure 1. Morphological characterization of blank GDE and gold decorating GDE (synthesized at $35{ }^{\circ} \mathrm{C}$ ). (a) SEM micrograph of the bare GDE electrode. (b-i) (HR)SEM with different magnifications of nanostructured gold particle growth on GDE: (b-d) Overview SEM, (e-g) near view, and (h, i) close view that shows HRSEM micrographs.

Figures 1b-i display the SEM and HRSEM pictures with different magnifications of the asfabricated GDE-Au at $35{ }^{\circ} \mathrm{C}$, which qualitatively demonstrate the successful synthesis by the revisited "halide-regulated method" using L-ascorbic acid as a reducing agent. ${ }^{29}$ The preliminary results from this method in terms of SEM and HRSEM images of nanostructured gold grown on GDE are reported in Figures S2; using different halides $\mathrm{Cl}^{-}, \mathrm{Br}^{-}$, and $\mathrm{I}^{-}{ }^{29}$ It can be observed that 
the gold particles are preferentially and mainly deposited on the surface of the first 2 or 3 layers of microfibers of the GDE out of approximately 27. These results are similar to earlier findings with $\mathrm{Au}, \mathrm{Pt}$, and Pd nanostructured metals through chemical reduction on a GDE and for which the augmentation of precursors concentration does not change the conclusion. ${ }^{29}$ This would mean that the first step of the reduction of metal salts by the reducing agent occurs on the outer fibers. Then, this first seeding layer of resulting particles serves as an active site where further reduction takes place and promotes the diffusion of metal salts from the interior towards the surface of the GDE. The crystals' size range is 5-7 $\mu \mathrm{m}$ for individual particles (Figure 1g) and 10-15 $\mu \mathrm{m}$ for clusters (Figure 1e). Each individual nanostructured particle or cluster of particles is composed of 3D self-assembly of sheets of about ten nanometers thick. Early-stage SEM observations (Figure S3) for the reaction time of 2 and 5 min showed that this desert rose-like morphology was present at the beginning. Figure S4 reports the energy-dispersive X-ray (EDX) analyses, which demonstrate that those particles are actually metallic gold since no presence of bromide or chloride was observed. The present nanostructured particles are slightly different from those initially obtained by the halide-regulated growth, HRSEM showed sponge-like 3D structures with gold particles of $600 \pm 200 \mathrm{~nm}$ and consisting of intertwined nanoplates of $50 \pm 10 \mathrm{~nm} .^{29}$ The present results could, therefore, be explained by the fact that the synthesis was realized under inert atmosphere and in a much more acidic medium $\left(2.4 \mathrm{mM} \mathrm{HAuCl}_{4}\right.$ in $1.8 \mathrm{M} \mathrm{HNO}_{3}, \mathrm{pH}$ 0) whereas the initial methodology was performed in $2.4 \mathrm{mM} \mathrm{HAuCl}_{4} \cdot 3 \mathrm{H}_{2} \mathrm{O}$.

Scheme 1 shows the illustration of the different steps in the present study. The introduction of the ionic ligand $\mathrm{Br}^{-}$in the reaction mixture results in the conversion of $\left[\mathrm{AuCl}_{4}\right]^{-}$ion-complexes $\left(\mathrm{p} K_{\mathrm{d}}=25\right)$ into the more stable $\left[\mathrm{AuBr}_{4}\right]^{-}$ones $\left(\mathrm{p} K_{\mathrm{d}}=32\right) .{ }^{34}$ The ionic radii of bromide is larger compared to chloride $\left(\mathrm{r}\left(\mathrm{Br}^{-}\right)=195 \mathrm{pm}, \mathrm{r}\left(\mathrm{Cl}^{-}\right)=181 \mathrm{pm}\right)$. Based on that and the specific adsorption of $\mathrm{Br}^{-}$on the crystallographic facet (111) of gold, ${ }^{35-37}$ the complete replacement of chloride with bromide should increase the steric hindrance around the metallic cation and slow down the $\mathrm{Au}(\mathrm{III})$ to $\mathrm{Au}(0)$ reduction rate. Indeed, $E^{\circ}\left(\left[\mathrm{AuBr}_{4}\right]^{-} / \mathrm{Au}\right)=0.85 \mathrm{~V}$ vs. SHE, which is smaller than $E^{\circ}\left(\left[\mathrm{AuCl}_{4}\right]^{-} / \mathrm{Au}\right)=1.00 \mathrm{~V}$ vs. SHE. This will further control the seed growth towards an anisotropic mechanism. Specifically, the difference between the standard redox potential $\Delta E^{\circ}(\mathrm{V})$ between the reducing agent couple (ascorbic acid) and that of $\mathrm{Au}(\mathrm{III}) / \mathrm{Au}(0)$ defines that equilibrium rate constant $\left(\log K=\frac{\Delta E^{\circ}}{0.06 n}, n=\right.$ exchange number of electrons, which 
is here equal to six). Furthermore, the growth anisotropy describes the condition in which the growth rates are not equal in all crystallographic ( $h k l)$ directions. The surface energies and thus the growth rates of the crystal faces dictate the final shape of a nanoparticle. For a face-centered cubic symmetry metal like gold, the (111) plane has the smallest of the surface energies compared to the (100) or (110) planes, so that nanoparticles enclosed by the (111) facets are often obtained. Experimentally, the modulation of the growth along a certain orientation rather than others is triggered by the specific adsorption of capping agent molecules on targeted ( $h k l)$ facets, which results in the formation of 1D, 2D, and 3D materials. In the present study, bromide ion was used as an ionic capping agent so that the ion could be easily washed out at the completion of synthesis.
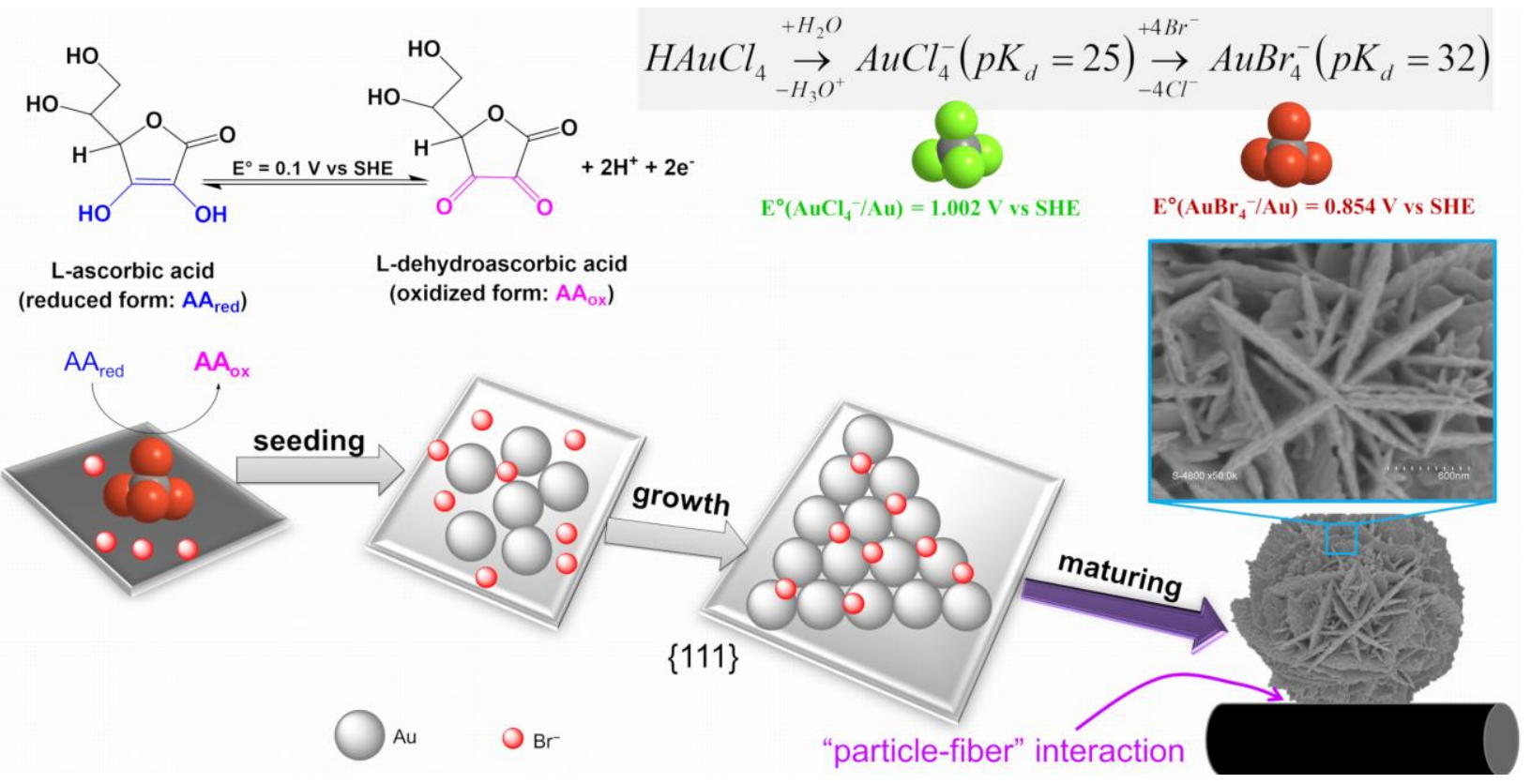

Scheme 1. Sketch of the desert rose-like gold crystal growth on the fiber of a carbon paper.

Similar types of structures have been reported for $\mathrm{Ag}^{38}$ and $\mathrm{Au}^{39,40}$ which are referred to as "mesoparticles or mesocrystals". It is reported that, those crystals are three-dimensional wellordered superstructures of particles resulting from the mechanism of the particle-mediated growth, which involves an organized assembly of separate sub-units of nanoparticles. ${ }^{38,39,41-43}$ The mechanism that was identified for the formation of the present nanostructured gold particles on GDE by nanoparticle-mediated growth, which is not a simple aggregation of individual 
particles with each other, has been described as follows. In the starting, $\left[\mathrm{AuBr}_{4}\right]^{-}$ion-complexes are chemically reduced to Au atoms by the L-ascorbic acid (L-dehydroascorbic acid as the byproduct), which leads to an increase of the concentration of Au atoms on the GDE surface with time, while the precursor $\left(\left[\mathrm{AuBr}_{4}\right]^{-}\right)$concentration diminishes. When the point of supersaturation is reached, $\mathrm{Au}$ atoms start to aggregate into small clusters on the GDE surface known as nuclei or seeds. Those seeds rapidly grow into nanocrystals, and the amount of the primary and individual Au atoms decreases when nanocrystals increase in size, until the growth stops due to the concentration of the building block units, which falls below the supersaturation threshold that defines an equilibrium state. In these particular conditions, a phenomenon called "oriented attachment or oriented aggregation" occurs, i.e., the already produced gold nanoparticles are aligned in a similar crystallographic orientation to ensure that the interface energy is minimized. ${ }^{38,42-44}$ The driving force of this stage is traditionally provided by the elimination of solvents or moieties from the surface of nanoparticles and the establishment of new chemical bonds via epitaxial connections. ${ }^{42,43}$ The final stage is the reduction of the remaining $\left[\mathrm{AuBr}_{4}\right]^{-}$ion-complexes by the L-ascorbic acid directly on the oriented Au nanoscale crystals to form micro-crystals. Herein, the most likely scenario involves bromide ions that regulate the growth rate along $(\mathrm{hkl})$ directions to yield desert rose-like Au crystals. Indeed, Xin et $a l .{ }^{36}$ showed that bromide determines the anisotropic growth of gold into nanoplates enclosed by (111) facets on graphene multilayers. In the present study, the 3D structure of GDE is different from the graphene sheets, which indicates that (111) could be one of the preferential directions. In the next sections, the use of additional characterization techniques of PbUPD and HRTEM will enable access to the full information.

To interrogate a possible influence of the temperature of the synthesis reactor on the morphology of the particles, we prepared additional GDE-Au materials at 5, 10, 20 and $40{ }^{\circ} \mathrm{C}$. For a temperature-dependent process, it is expected that the augmentation or decrease of the temperature affect the reaction rates through the Arrhenius's relationship. The results of the GDE-Au material obtained at a temperature of $35{ }^{\circ} \mathrm{C}$ were discussed above, SEM images of Figure 1. Figures 2a-d shows SEM/HRSEM micrographs of GDE-Au materials with different magnifications for the temperatures of $5,10,20$, and $40{ }^{\circ} \mathrm{C}$ (from top to down for the sequence). HRSEM images clearly demonstrate that all materials follow the same anisotropic gold particle growth on GDE, leading to the desert rose-like structure. The impact of the temperature is only 
visible for the density of the particles on the microfibers, which increases with the temperature. This finding would, therefore, mean that only the first stages in the reduction of $\left[\mathrm{AuBr}_{4}\right]^{-}$ioncomplexes by the L-ascorbic acid and the subsequent nucleation are impacted. The results are the production of a significant amount of gold nuclei, resulting in a high degree of microfiber coverage. Consequently, a higher amount of gold nuclei will lead to a larger number of desert rose-like gold crystals.
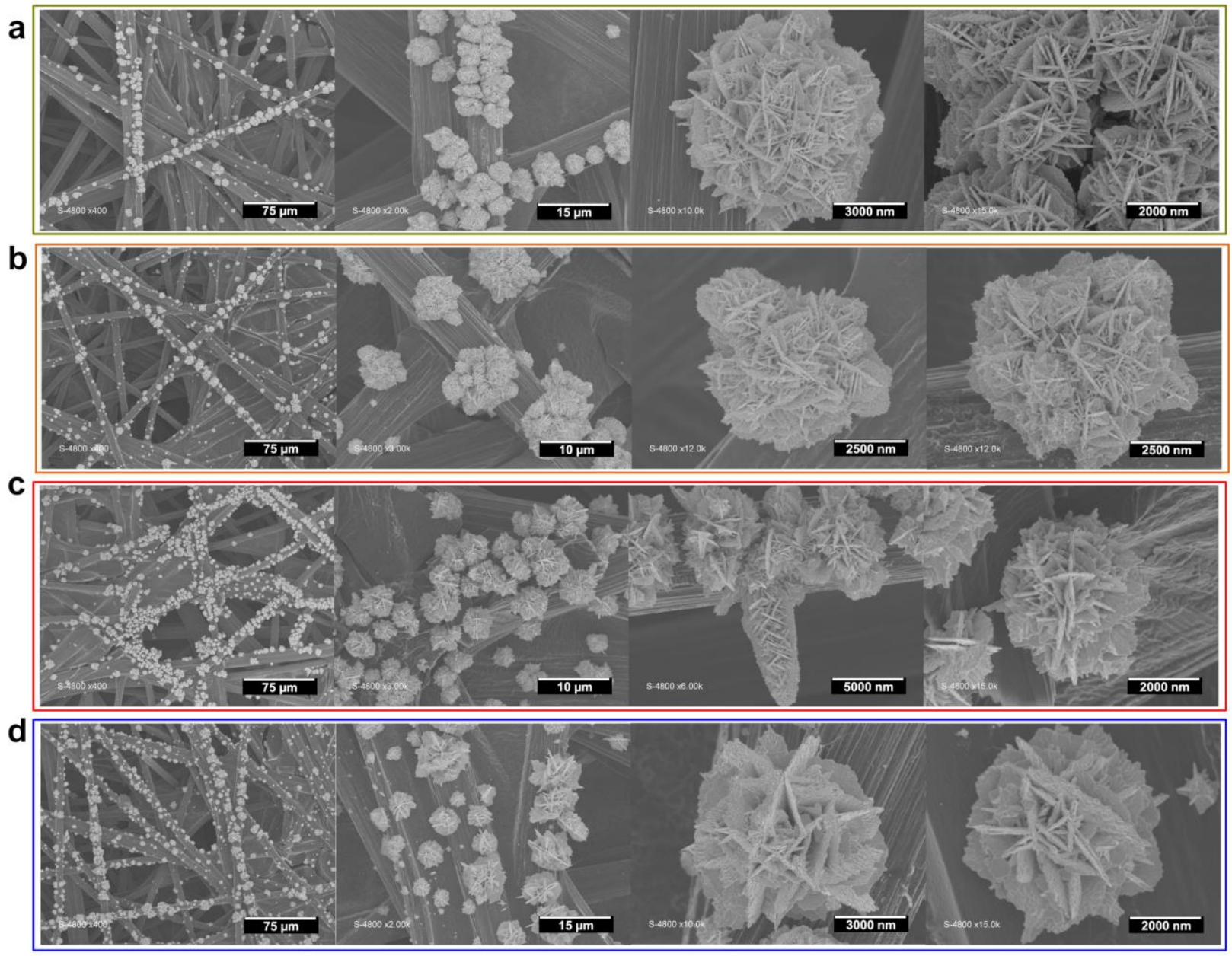

Figure 2. Morphological characterization of the nanostructured gold decorating GDE. (a-c) SEM and HRSEM images for the nanostructured gold particle growth on GDE at the reaction temperature of: (a) $5{ }^{\circ} \mathrm{C}$, (b) $10^{\circ} \mathrm{C}$, (c) $20^{\circ} \mathrm{C}$, and (c) $40{ }^{\circ} \mathrm{C}$.

The preceding discussion shows that not only were we able to tightly regulate the formation of desert rose-like gold mesocrystals directly at one face of a GDE support, but also, the reaction 
temperature does not impact the morphology significantly. We then questioned whether the nonvisible effects of temperature on the morphology of the particles could be a major factor in the electrocatalytic activity. This is due to the simple reason that morphology is not the only parameter that dictates electrocatalytic performance. To elucidate that point, we thus studied the ability of the materials to catalyze the glycerol electrooxidation reaction, investigating the GDE$\mathrm{Au}$ electrodes obtained at $5,10,20,35$, and $40{ }^{\circ} \mathrm{C}$. Figure 3 a presents the open circuit potential (OCP) recorded in $0.1 \mathrm{M} \mathrm{NaOH}+0.1 \mathrm{M}$ glycerol, after having degassed with nitrogen for about thirty minutes. Basically, the OCP is the apparent potential at which the reaction could start. For an organic molecule electrooxidation, it is expected that the OCP (potential at zero current) has the lowest possible value to minimize the additional energy required for the reaction to take place. Taking into account the standard deviation, typically $20-50 \mathrm{mV}$, it can be deduced from Figure $3 \mathrm{a}$ that the onset potential of the five types of electrodes are the same $(0.65 \pm 0.02 \mathrm{~V}$ vs. RHE). Furthermore, the iR-uncorrected cyclic voltammograms (CVs) normalized by the electrode area (Figure $3 b$ ) confirmed the previous results. Indeed, the onset potential $\left(E_{\text {onset }}\right)$ is $E_{\text {onset }} \approx 0.7 \mathrm{~V}$ vs. RHE. During the forward scan, a peak current density was reached at $E_{\text {peak }}=$ $1.4 \mathrm{~V}$ vs. RHE. Then, the current density decreases because of the formation of inactive gold oxides. During the backward scan, the reduction of those oxides into metallic species allows new reactant molecules to adsorb and get oxidized again (as demonstrated by electroanalytic studies $^{45}$ ), thus leading to a new oxidation peak at 1.1-1.4 V vs. RHE. For the forward scan, the peak current density was $j_{\mathrm{p}}=21,23,20,27$, and $31 \mathrm{~mA} \mathrm{~cm}^{-2}$ for GDE-Au obtained at 5, 10, 20, 35 , and $40{ }^{\circ} \mathrm{C}$, respectively. Since the materials have similar morphology and the onset potential is the same for the different electrodes, the observed differences might be attributed to the number of active sites. Specifically, the electrochemically active surface area is ECSA $=0.12$, $0.22,0.18,0.26$ and $0.35 \mathrm{~cm}^{2}$ for $5,10,20,35$, and $40{ }^{\circ} \mathrm{C}$, respectively. Those significant changes of the electrocatalytic activity and ECSA are consistent with the increase in the density of gold particles on the outer fibers of the GDE with the increase in temperature of the synthesis reactor, as previously observed. Of course, taking into account the active surfaces, the trend would be reversed for the specific current density. However, from an application point of view, it is more convenient to look at the result in terms of geometric surface area. So, it is expected to obtain the highest current density per geometrical surface. Based on this strategy, the outcomes 
of Figure 3 show that the reaction temperature of $35-40{ }^{\circ} \mathrm{C}$ is sufficient to get the GDE-Au electrode that will enable to reach the highest current when applied to an electrolyzer.
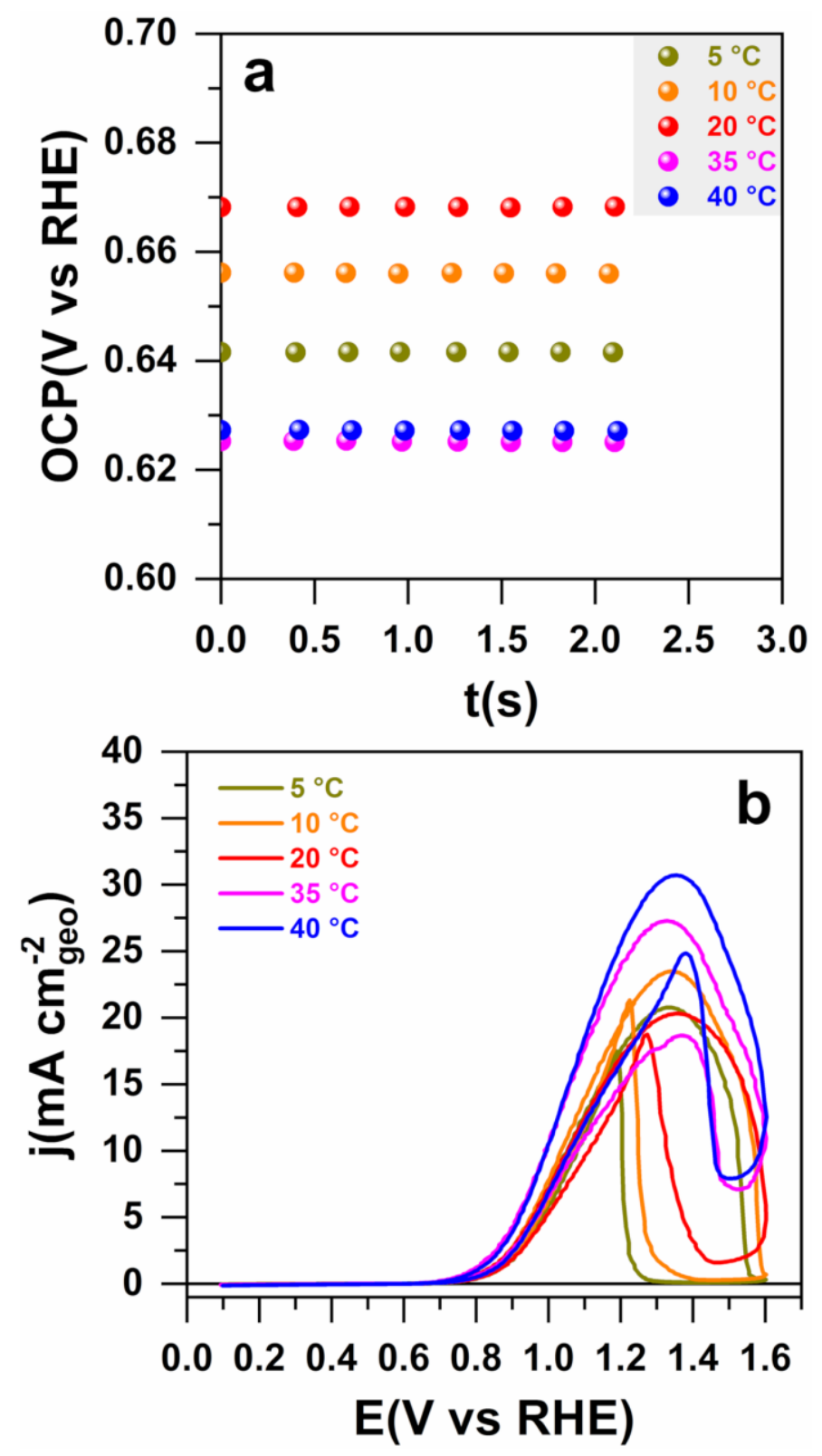

Figure 3. Electrochemical performance of the as-synthesized GDE-Au material at different temperatures. (a) Recorded OCP upon stabilization in $0.1 \mathrm{M} \mathrm{NaOH}+0.1 \mathrm{M}$ glycerol. (b) iRuncorrected $\mathrm{CVs}$ recorded in $0.1 \mathrm{M} \mathrm{NaOH}+0.1 \mathrm{M}$ glycerol at $50 \mathrm{mV} \mathrm{s}^{-1}$. Experiments were performed at $25^{\circ} \mathrm{C}$.

XRD, PbuPD, and HRTEM Investigations. 
To gain further insights into the as-fabricated GDE-Au electrode materials, we next performed a number of physicochemical characterizations and electrochemical probing. We specifically utilized X-ray diffraction (XRD) to determine the crystallographic structure of the as-synthesized materials. Figure $4 \mathrm{a}$ shows the obtained patterns of the representative samples of GDE-Au obtained at $35^{\circ} \mathrm{C}$ and GDE as the blank material. For both GDE and GDE-Au materials, the peak localized at $53.9^{\circ}$ corresponds to the (004) reflection peak of graphite coming from the carbon support (as well as a strong (002) peak of graphite at $26.4^{\circ}$, not shown for clarity). The presence of gold in GDE-Au is shown by the peaks localized at $38.2^{\circ}, 44.4^{\circ}, 64.5^{\circ}$, and $77.6^{\circ}$, which correspond to the crystallographic orientations (111), (200), (220), and (311) of facecentered cubic of gold, respectively. We next utilized the CV recording in the electrolyte and the model of underpotential deposition of lead ( $\left.\mathrm{Pb}_{\mathrm{UPD}}\right)$, which are efficient tools to characterize the surface of different types of gold and the evaluation of their crystallographic structures. ${ }^{46-51}$ To these ends, two types of electrodes were considered, GDE-Au electrode by Au growth on one face of GDE $\left(n(\mathrm{KBr}) / n\left(\mathrm{HAuCl}_{4}\right)=100\right)$ and GDE-Au electrodes by Au growth on both faces of GDE. For the latter, the synthesis was carried out either in the presence of $\mathrm{KBr}$ $\left(n(\mathrm{KBr}) / n\left(\mathrm{HAuCl}_{4}\right)=100, \mathrm{GDE}-\mathrm{Au} \_\mathrm{KBr}-100\right)$ or in the absence of $\mathrm{KBr}\left(n(\mathrm{KBr}) / n\left(\mathrm{HAuCl}_{4}\right)=0\right.$, GDE-Au_KBr-0) in order to interrogate the effect of the halide, i.e. bromide. Figures $4 \mathrm{~b}$ and $4 \mathrm{c}$ depict the recorded steady-state voltammograms. The voltammograms in the electrolyte show well-defined electrochemical features of gold. The first region (0.1-0.7 V vs. RHE) represents the capacitive current and the second the chemisorption of $\mathrm{OH}^{-}$resulting in the formation of $\mathrm{Au}(\mathrm{OH})_{\mathrm{x}}$ as well as their oxidation to form $\mathrm{AuO}_{\mathrm{x}}$ above $1.2 \mathrm{~V}$ vs. RHE. Then, the formed oxides during the positive scan of the potential are reduced during the reverse scan with a peak centered at a potential of $1.1 \mathrm{~V}$ vs. RHE. Figure 4c clearly shows that the introduction of potassium bromide during the synthesis enables fabricating an electrode material with an augmented electrochemically active surface area since the current associated to the reduction of the oxides of GDE-Au_KBr-100 is greatly larger than that of GDE-Au_KBr-0. Even though the PbuPD for different electrodes exhibits the same overall profile of an adsorption-desorption reversible process, the peak currents have much higher intensity in the case of GDE-Au_KBr-100 in comparison with GDE-Au_KBr-0. During the negative potential sweep, the strong peaks appearing at 0.55 and $0.41 \mathrm{~V}$ vs. RHE correspond, respectively, to the lead deposition on (110) and (111) facets of gold. ${ }^{46,47,50}$ Due to the reversibility of those adsorption-desorption processes, 
the reversible desorption of the lead on (111) and (110) corresponds to the peaks at 0.45 and 0.58 V vs. RHE during the backward scan, respectively. As we previously showed, ${ }^{29,46}$ a careful look at the region between those peaks reveals the presence of a shoulder around $0.50 \mathrm{~V}$ vs RHE that corresponds to (100) facet. Hence, the presence of low-coordination number (111) facet is indeed confirmed by both XRD and PbuPD. The complementary observation (100) and (110) by PbuPD can be correlated with the presence of the diffraction peaks associated to the high-index facets of (200) and (220) as previously evidenced by XRD. The comparison of the profiles of the obtained peaks of the $\mathrm{Pb}_{\mathrm{UPD}}$ for each facet with the existing literature of single and nanoscale crystals of gold should indicate that the (111) facet is predominant. ${ }^{46-51}$ By considering the intensities and areas of the peaks, the PbuPD characteristics in Figure $4 \mathrm{c}$ clearly reveal that the bromide ion predominantly favors the crystallographic direction (111). This set of data greatly supports the hypothesis of the growth of gold particles in different orientations resulting in desert rose-like nanostructured gold particles containing various facets. To date, Miller's low index facets (100), (110) and (111) are thought to increase the electrocatalytic activities of nanostructured gold materials. $^{46,50,52}$

To further elucidate the structural and textural characteristics of the as-synthesized nanostructured gold materials, a typical sample was prepared using a double beam focused ion beam (dbFIB) microscope. Figure $4 \mathrm{~d}$ displays the high-solution transmission electron microscopy (HRTEM) image and its corresponding picture of the Inverse Fast Fourier Transition (IFFT) is shown in Figure 4e. Both configurations allow identifying the crystal structures unambiguously. For the analyzed part of the sample, the measured interplanar space of $0.24 \mathrm{~nm}$ is consistent with the (111) crystalline plane of the face-centered cubic symmetry of the gold. This finding supports the above hypothesis of the promotion of (111) face of Au by the bromide halide. The present analysis at the atomic level corroborates the earlier physical characterization through XRD and electrochemical probing via PbuPD. Indeed, for a lattice parameter a $=4.08 \AA$ of gold (face-centered cubic structure), the values of the interplanar space $d_{(h k l)}=\frac{a}{\sqrt{h^{2}+k^{2}+l^{2}}}$ are $0.408,0.288,0.236$, and $0.204 \mathrm{~nm}$ for (100), (110), (111) and (200), respectively. In our preliminary study, ${ }^{29}$ other interplanar spaces of $0.14,0.19$, and $0.29 \mathrm{~nm}$ were observed from HRTEM pictures acquired at different locations. Hence, taking into account all the results obtained here from XRD and PbuPD, we can argue that the absence of those lattice fringes results 
from the narrow area of analysis in this study, or it might be due to the peculiar planar geometry of the crystals as observed by SEM in Figures 1 and 2.
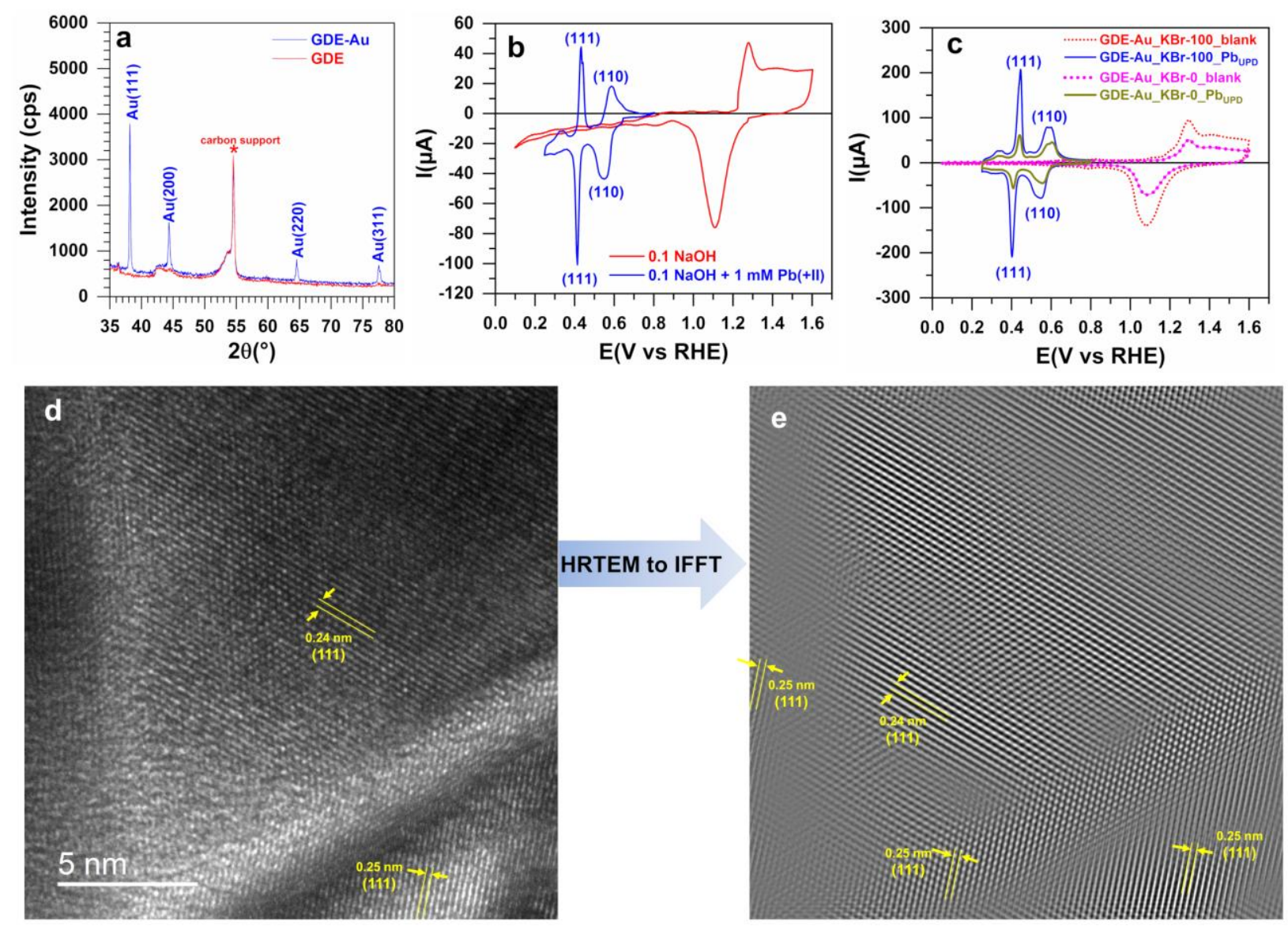

Figure 4. Crystallographic orientation characterization. (a) XRD patterns of the nanostructured gold particle growth on GDE (GDE-Au) and the control material (GDE). (b) CVs of the GDE$\mathrm{Au}$ electrode at $50 \mathrm{mV} \mathrm{s}^{-1}$ scan rate of the blank in $0.1 \mathrm{M} \mathrm{NaOH}$ and UPD of lead in $0.1 \mathrm{M}$ $\mathrm{NaOH}$ containing $\mathrm{Pb}\left(\mathrm{NO}_{3}\right)_{2}$ at $1 \mathrm{mM}$ : Au growth on one face of GDE (are $=0.25 \mathrm{~cm}^{2}$ ). (c) CVs of the blank and UPD of lead obtained at $50 \mathrm{mV} \mathrm{s}^{-1}\left(0.1 \mathrm{M} \mathrm{NaOH}+1 \mathrm{mM} \mathrm{Pb}\left(\mathrm{NO}_{3}\right)_{2}\right)$ : GDE-Au electrode synthesized at $n(\mathrm{KBr}) / n\left(\mathrm{HAuCl}_{4}\right)=100\left(\mathrm{GDE}-\mathrm{Au} \_\mathrm{KBr}-100\right)$ and at $n(\mathrm{KBr}) / n\left(\mathrm{HAuCl}{ }_{4}\right)$ $=0\left(\right.$ GDE-Au_KBr-0): Au growth on both faces of GDE $\left(\right.$ area $\left.=2 \times 0.25=0.5 \mathrm{~cm}^{2}\right)$. Transform an HRTEM micrograph (d) to IFFT image with lattice fringes (e).

\section{Performance Comparison with the Commercial Vulcan-Au Catalyst.}


To assess the potential for electrocatalytic applications of the as-fabricated freestanding GDE$\mathrm{Au}$ electrode materials obtained by $\mathrm{Au}$ growth on one face of GDE (referred herein to as $\mathrm{CP}-\mathrm{Au}$, about $100 \mu \mathrm{g}_{\mathrm{Au}} \mathrm{cm}^{-2}$ ), we carried out a set of control experiments for the glycerol oxidation reaction. The electrocatalytic activity was studied in $1.0 \mathrm{M} \mathrm{NaOH}+0.1 \mathrm{M}$ glycerol. To make a fair comparison with the state-of-the-art Vulcan-Au $(20 \mathrm{wt} \%)$ as well as the relevant metallic electrocatalysts in alkaline media from literature, we utilized different metrics for the current density normalization. Figure S5 illustrates the method used for the ECSA by CV (Table S1). Among our investigated methods, the current was normalized by using the electrode area (Figure 5a), ECSA (Figure 5b), gold weight (Figure S6a), and simultaneously by the mass and ECSA of the gold (Figure S6b). The different loading of $\mathrm{Au}$ for the commercial $\mathrm{Au} / \mathrm{C}$ (Vulcan-Au-38, Vulcan-Au-76, Vulcan-Au-152, the numbers indicate the mass of the gold in micrograms per square centimeter) was used to make sure that the comparison can be neither overestimated nor underestimated. For the CVs that are based on the electrode surface, the peak current density is, $j_{\mathrm{p}}=78,47,55$, and $52 \mathrm{~mA} \mathrm{~cm}{ }^{-2}$ for CP-Au, Vulcan-Au-38, Vulcan-Au-76, and Vulcan-Au-152, respectively. Those peak current densities of those Vulcan-Au electrodes are 1.6, 1.4, and 1.5 times lower in comparison with CP-Au. The specific current density based on ECSA is shown in Figure 5b, which indicates that $\mathrm{CP}$-Au still outperformed the commercial catalyst. In terms of the mass-activity, $j_{\mathrm{p}}$ was evaluated to be $0.8,1.3,0.7$, and $0.07 \mathrm{~A} \mathrm{mg}_{\mathrm{Au}}{ }^{-1}$ for $\mathrm{CP}-\mathrm{Au}, \mathrm{Vulcan}-\mathrm{Au}-38$, Vulcan-Au-76, and Vulcan-Au-152, respectively. Based on the metal loading of the as-fabricated $\mathrm{CP}-\mathrm{Au}\left(100 \mu \mathrm{g}_{\mathrm{Au}} \mathrm{cm}^{-2}\right)$, it cannot be concluded that the present desert rose-like gold crystals exhibit an enhanced electrocatalytic activity towards glycerol electrooxidation. By taking into account both ECSA and gold content, $j_{\mathrm{p}}$ was determined to be $1.33 \mathrm{~cm}_{\mathrm{Au}}{ }^{-2} \mathrm{mg}_{\mathrm{Au}}{ }^{-1}$ (CP-Au), 0.30 $\mathrm{cm}_{\mathrm{Au}}{ }^{-2} \mathrm{mg}_{\mathrm{Au}}{ }^{-1}$ (Vulcan-Au-76), and $0.01 \mathrm{~A} \mathrm{~cm}_{\mathrm{Au}}{ }^{-2} \mathrm{mg}_{\mathrm{Au}}{ }^{-1}$ (Vulcan-Au-152). This corresponds to an increase of nearly one order of magnitude in catalytic activity for an equivalent gold content. Table S2 summarizes the performance of nanostructured mono- and bi-metallic catalysts for the electrooxidation of glycerol in basic solutions, which have a peak current density of $j_{\mathrm{p}}=$ $20-290 \mathrm{~mA} \mathrm{~cm}{ }^{-2}$ based on the area of the electrode or $j_{\mathrm{p}}=0.2-18 \mathrm{~A} \mathrm{mg}_{\mathrm{Au}}{ }^{-1}$, and where metal content is fairly high of 16-500 $\mu \mathrm{g}_{\mathrm{Au}} \mathrm{cm}^{-2} \cdot{ }^{20,28,53-58}$ Except for few examples of nanoalloynanoporous $\mathrm{AuAg}^{19}$ and $\mathrm{Pt}-\mathrm{PtCo},{ }^{53,57}$ it can, therefore, be deduced that the performance of the asfabricated GDE-Au freestanding material is superior to the relevant activities reported in the literature for gold-, palladium-, and platinum-based electrocatalysts. ${ }^{20,54-56,58-62}$ To our 
knowledge, this is the first time a free-standing electrocatalyst made of desert rose-like nanostructured gold has been obtained directly onto carbon fiber electrode and demonstrate high performance towards the glycerol electrooxidation. The enhanced electrocatalytic performance of the present GDE-Au results from the absence of organic impurities or binding substances on the surface of the nanostructured particles, the particular morphology of the latter, and the strong particle-support interaction.
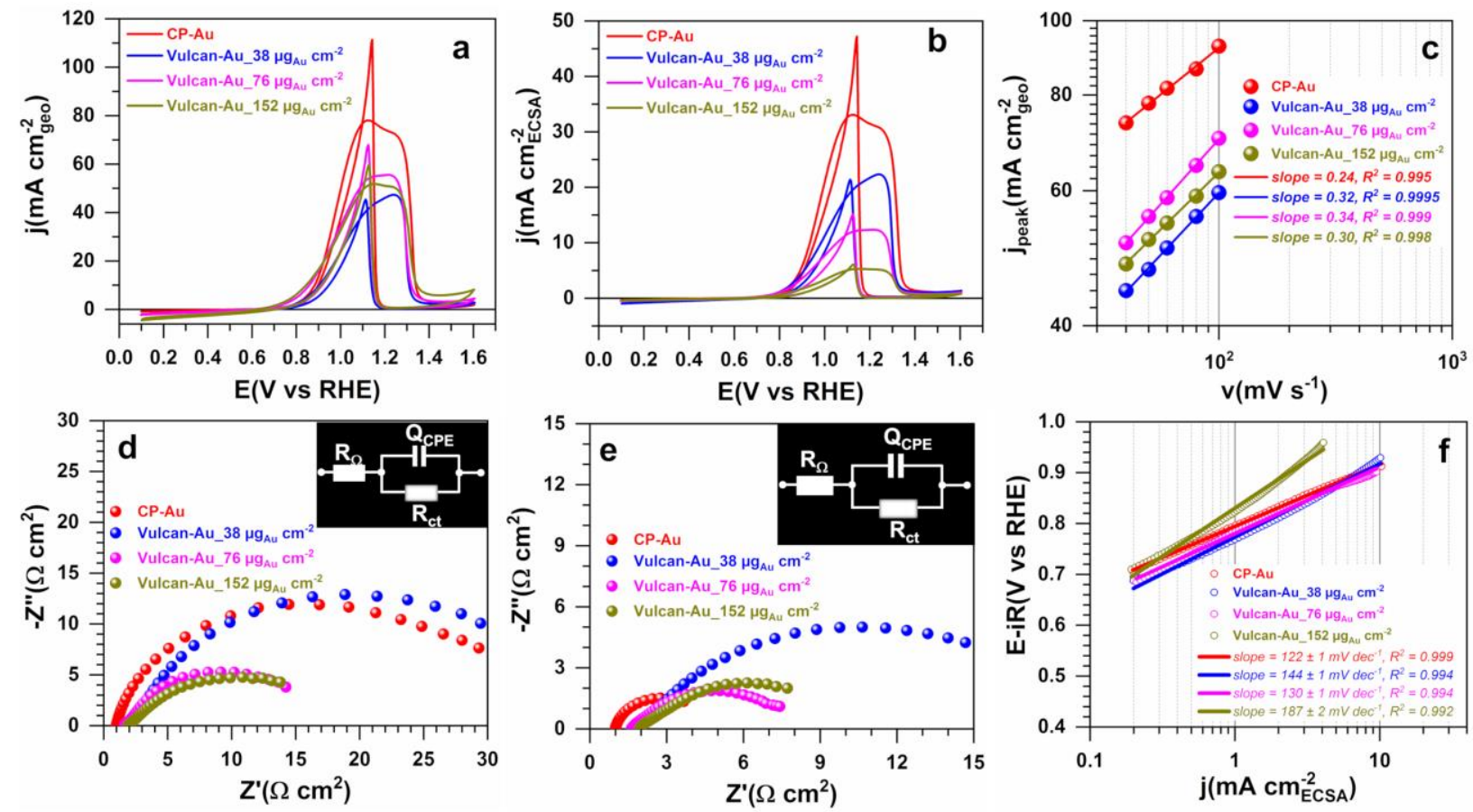

Figure 5. Comparison of the performance of the commercial material $\mathrm{Au} / \mathrm{C}$ referred to as Vulcan-Au and the as-fabricated GDE-Au material referred to as CP-Au. (a, b) iR-uncorrected CVs related to: (a) the electrode area, and (b) the specific active surface of gold. (c) Plot of the peak current density $\left(j_{\text {peak }}\right)$ vs. the scan rate $(v)$ in log-log scale. (d, e) Complex-plane Nyquist impedance (normalized by the electrode area and inset the equivalent electrical circuit) at: (d) $E_{\text {appl }}=0.84 \mathrm{~V}$ vs. RHE, and (e) $E_{\text {appl }}=0.94 \mathrm{~V}$ vs. RHE. (f) iR-free Tafel plots from the panel (b). The electrolyte was $1.0 \mathrm{M} \mathrm{NaOH}$, the glycerol was at $0.1 \mathrm{M}$, the temperature was $25^{\circ} \mathrm{C}$ and the scan rate for CVs was $50 \mathrm{mV} \mathrm{s}^{-1}$. 
We next investigated the glycerol electrooxidation by changing the sweep rate of the potential during cyclic voltammetry in an attempt to interrogate the reaction process electrochemically. Figures S6c-f displays the CVs collected at various sweep rates (v). Figure 5c shows the plots of $\log \left(j_{\mathrm{p}}\right)$ vs $\log (v)$. The obtained slope of $0.2-0.3$, which falls in the case where the adsorption, diffusion, and electron transfer limit the overall reaction. Indeed, the seminal study on the effect of the scan rate on the peak current density $\left(\log \left(j_{\mathrm{p}}\right)\right.$ vs $\log (v)$, the relationship is also valid for the peak current without normalization) of the electrooxidation of organic molecules resumed that: (i) a slope of 1 is the pure adsorption, (ii) a slope of 0.5 is the pure diffusion, (iii) a slope of $0.5-1$ is a mixed regime of adsorption and diffusion, (iv) a slope below 0.5 is a complicated kinetics involving parallel or successive reactions (can be referred to as cascade reactions). ${ }^{63}$ It is thus obvious that the case (iv) is a combination of the case (iii) and the electron transfer. This conclusion was expected, since the glycerol electrooxidation reaction is often considered to be a process involving the transfer of at least two electrons and two protons to oxidize the secondary or primary alcohol group into a stable product. ${ }^{19,20,58,62}$ Therefore, the reactant/product diffusion/adsorption and the electron transfer can simultaneously limit the overall reaction kinetics.

The electrochemical impedance spectroscopy (EIS) was then utilized to better understand the origin of the high catalytic efficiency of the GDE-Au electrode material. EIS allows modeling the electrocatalytic interface. ${ }^{64,65}$ Figures $5 \mathrm{~d}$-e show the plots of the complex-plane Nyquist impedance at two potentials, $E_{\mathrm{appl}}=0.84 \mathrm{~V}$ vs. RHE (Figure 5d) and $0.94 \mathrm{~V}$ vs RHE (Figure 5e). The combination $R_{\Omega}+Q_{\mathrm{CPE}} / / R_{\mathrm{ct}}$ is the representative equivalent electrical circuit that best describes the electrocatalytic interface. The ohmic resistance also referred to as the uncompensated resistance was modeled by $R_{\Omega}$, the constant phase element that represents an imperfect capacitance of the double-layer was symbolized by $Q_{\mathrm{CPE}}$ and the charge transfer resistance was schematized by $R_{\mathrm{ct} .}{ }^{64,65}$ Basically, $R_{\mathrm{ct}}$ is inversely dependent to the standard rate constant of the reaction, which is proportional to the exchange current density (function of the Tafel slope and equilibrium redox potential). ${ }^{66,67}$ Therefore, it is expected to have the lowest value of $R_{\mathrm{ct}}$ for a faster electron transfer capacity for a given overpotential (higher value of the rate constant). The ohmic resistance is $R_{\Omega}=1 \Omega \mathrm{cm}^{2}$ for CP-Au and $2 \Omega \mathrm{cm}^{2}$ for Vulcan-Au. Those values correspond to $\sim 4 \Omega$ by taking into account the electrode area, which is the typical value of conductive electrocatalytic materials in $1 \mathrm{M} \mathrm{NaOH}$ at room temperature. $R_{\square}$ depends on 
the electrolyte conductivity, the position of the reference electrode relative to the working electrode, and the geometry of the working electrode, which were kept unchanged during our measurements. Furthermore the charge transfer resistances at $0.94 \mathrm{~V}$ vs. RHE are $R_{\mathrm{ct}}=5 \Omega \mathrm{cm}^{2}$ (CP-Au), $19 \Omega \mathrm{cm}^{2}$ (Vulcan-Au-38), $7 \Omega \mathrm{cm}^{2}$ (Vulcan-Au-76), and $9 \Omega \mathrm{cm}^{2}$ (Vulcan-Au-152). The lowest value of $R_{\mathrm{ct}}$ for the CP-Au electrode confirms its high ability to transfer electrons and deliver high current. We finally evaluated the Tafel slope expressed as $\mathrm{mV} \mathrm{dec}^{-1}$, a semiquantitative measure of the kinetics and/or mechanisms of a charge transfer process. ${ }^{66}$ Indeed, the slope of the Tafel indicates the electron transfer ability between the surface of an electrode and the substrate under study. In practice, a catalytic material having a small Tafel slope is better because a lower value implies that increasing the activity by an order of magnitude $\left(\mathrm{dec}^{-1}\right)$ necessitates low overpotential $(\mathrm{mV})$, which implies faster charge transfer kinetics. Tafel plots by current density were reported in Figure 5f. The evaluated values are 122, 144, 130, and $187 \mathrm{mV}$ $\mathrm{dec}^{-1}$ for CP-Au, Vulcan-Au-38, Vulcan-Au-76, and Vulcan-Au-152, respectively. To confirm this trend, we also determined the Tafel slope by the alternative method of $E-i R$ vs. $\log \left[R_{\mathrm{ct}}{ }^{-1}\right]{ }^{68-}$

70 as reported in Figure S7. The determined values by this method are 130, 193, 174, and $218 \mathrm{mV}$ $\operatorname{dec}^{-1}$ for CP-Au, Vulcan-Au-38, Vulcan-Au-76, and Vulcan-Au-152, respectively. Hence, both methods demonstrate that the $\mathrm{CP}-\mathrm{Au}$ electrode has the lowest Tafel slope, which is consistent with the high electrochemical performance by $\mathrm{CV}$ mentioned above.

It is important to mention that the present electrocatalytic performance was obtained in halfcell experiments, i.e. in a three-electrode configuration. Hence, we emphasis that it is unknown how these free-standing GDE-Au electrodes would perform in an MEA when implemented in an electrolyzer and where the mass transport is critical. This dedicated investigation including a fair optimization is a future direction for the type of materials reported herein.

\section{CONCLUSION}

Metallic nanoparticles as electrocatalysts are traditionally produced as solution or powder before being re-dispersed in the presence of a binder to form a homogeneous catalytic ink for incorporating on the support. This strategy of nanostructured materials does not benefit from the metal-support interaction and sometimes suffers from the remaining surfactants on particles, which do not permit maximizing the catalytic performance in terms of available active sites, 
activity, and durability. We demonstrated herein a facile and simplified method for the direct growth of three-dimensional desert rose-like nanostructured gold particles directly at one face of a model carbon paper substrate, which is currently used in fuel cells and electrolyzers as a gasdiffusion electrode (GDE). The preparation of a membrane-electrode-assembly includes the GDE for better management of the reactant distribution and the achievement of high current densities. Our developed one-step method involved the chemical reduction of $\mathrm{Au}(\mathrm{III})$ ions using L-ascorbic acid as the reducing agent in tandem with bromide used as the ionic capping agent for easy removal after the synthesis. This bromide-regulated method allows synthesizing desert roselike nanostructured gold particles that were strongly anchored on the surface of the GDE's microfibers. The nanoparticle-mediated aggregation mechanism and the preferential adsorption of $\mathrm{Br}^{-}$on the (111) facet leaving behind dominant planar structured nuclei was used to explain the formation of those hierarchical 3D Au structures. The nanosheet self-assembly to yield desert rose-like gold particles resulted in a high electrocatalytic activity towards glycerol oxidation in alkaline media, which was larger than the commercial Vulcan-supported gold nanoparticles. We also point out that a future study in a complete electrolysis cell with a MEA is necessary to confirm the performance obtained herein by a half-cell setup. The present study outlines further directions for the fabrication of organic surfactant-free metallic nanostructured crystals as freestanding electrocatalysts for application in heterogeneous electrocatalysis.

\section{ASSOCIATED CONTENT}

Supporting Information. The following files are available free of charge. Additional SEM/HRSEM images of GDE; SEM images of GDE-Au materials obtained in the presence of $\mathrm{Cl}^{-}, \mathrm{Br}^{-}$and $\mathrm{I}^{-}$; Early stage (2 and $5 \mathrm{~min}$ ) SEM/HRSEM of GDE-Au; EDX of GDE-Au; additional CVs recorded $1 \mathrm{M} \mathrm{KOH}$; additional $\mathrm{CVs}$ recorded in $1 \mathrm{M} \mathrm{KOH}+0.1$ glycerol; Tafel plots by $R_{\mathrm{ct}}$; Table of the determination of the ECSA; and comparison of the performance of relevant metallic catalysts for the glycerol electrooxidation reaction from literature.

\section{AUTHOR INFORMATION}

\section{Corresponding Author}


*S.D.M.: E-mail: minteer@,chem.utah.edu

*D.C.: E-mail: david.cornu@enscm.fr

*Y.H.: E-mail: yaovi.holade@enscm.fr

Notes

The authors declare no competing financial interest.

\section{EXPERIMENTAL SECTION}

\section{Chemicals and Materials.}

GDE-based carbon paper electrode (AvCarb MGL190, $190 \mu \mathrm{m}$ thickness) was obtained from Fuel Cell Earth LL (USA). Nitric acid ( $\mathrm{HNO}_{3}, 65 \%$, Sigma-Aldrich), sodium hydroxide ( $\mathrm{NaOH}$, 99.4\%, Fisher Scientific), trihydrate tetrachloroauric acid $\left(\mathrm{HAuCl}_{4} \cdot 3 \mathrm{H}_{2} \mathrm{O}, 99.9 \%\right.$, SigmaAldrich), isopropanol ( $\mathrm{PrOH}, \geq 99.5 \%$, Sigma-Aldrich), potassium bromide ( $\mathrm{KBr}, 99 \%$, Alfer Aesar), lead nitrate $\left(\mathrm{Pb}\left(\mathrm{NO}_{3}\right)_{2}, \geq 99.0 \%\right.$, Sigma-Aldrich), L-(+) ascorbic acid (AA, $>99 \%$, Alfer Aesar), Nafion ${ }^{\circledR}$ suspension (5 wt $\%$, Sigma-Aldrich), commercial catalyst Au/C (20 wt $\%, \approx 4 \mathrm{~nm}$ particles size, Premetek Co., USA) were used as received. All ultrapure water (MQ) was 18.2 $\mathrm{M} \Omega \mathrm{cm}$ at $20^{\circ} \mathrm{C}$, obtained from a Milli-Q Millipore source.

\section{Chemical growth of Au onto 3D GDE: GDE-Au.}

The synthesis was performed as previously with few modifications. ${ }^{29}$ The as-received GDE was cut in a square to yield $5 \mathrm{~cm}$ high and $5 \mathrm{~cm}$ width. It was washed $3 \times$ by $\mathrm{iPrOH}$ under middle-shacking ( 5 min per round) using an orbital shaker (RSLAB-7PRO, RS Lab) followed by drying in an oven at $50{ }^{\circ} \mathrm{C}(1 \mathrm{~h})$, and referred to as $\mathrm{CP}$. For Au particle deposition onto one face of $\mathrm{CP}$, an electroplating tape (3M Company) was used so that the working geometric area is 25 $\mathrm{cm}^{2}$; however, given its $3 \mathrm{D}$ morphology, it is obvious that the real geometric surface area is larger than that value. The synthesis was carried out in an engineered double-jacket reactor (cleaned with "aqua regia" from one synthesis to another) that operated at different temperatures. Typically, $18.8 \mathrm{mg}$ of $\mathrm{HAuCl}_{4} \cdot 3 \mathrm{H}_{2} \mathrm{O}$ were dissolved with $20 \mathrm{~mL}$ of $1.8 \mathrm{M} \mathrm{HNO}_{3}$ and gently shaken for five minutes using the previous shaker. Then, $546 \mathrm{mg} \mathrm{KBr}(229 \mathrm{mM})$ was introduced and the solution was shaken for an additional five minutes. Next, the as-cleaned CP piece was 
introduced for further shaking while outgassing for ten minutes. Then, $1.912 \mathrm{~mL}$ of $0.1 \mathrm{M}$ of ascorbic acid was added at $0.3 \mathrm{~L} \mathrm{~h}^{-1}$ through a syringe pump (KD Scientific). The reaction proceeded under shaking and the color of the electrode changed from greyish to brown/red, which is typical of gold. After $1 \mathrm{~h}$ (except control experiments of 2 and $5 \mathrm{~min}$ ), the reaction was quenched by removing the electrode rapidly. Finally, the sample was thoroughly rinsed with ultrapure water and dried in the oven at $50{ }^{\circ} \mathrm{C}$ overnight. Once dried, the tape was easily peeled off. GDE-Au was similarly prepared as previously described ${ }^{29}$ for morphological comparison.

\section{Material Characterizations.}

A Hitachi S-4800 microscope was used for SEM analysis. A ZEISS EVOHD 15 microscope was used for EDX study. XRD patterns were collected in Bragg-Brentano mode from 20 to $80^{\circ}$ (in $2 \theta)$ using a PANalytical Xpert-PRO diffractometer operating at $40 \mathrm{kV}$ and $20 \mathrm{~mA}\left(\lambda\left(\mathrm{Cu}_{\mathrm{K} \alpha 1, \alpha 2}\right)=\right.$ $1.541 \AA$ ). Inductively coupled plasma optical emission spectrometry (ICP-OES) analysis was carried out on a spectrometer Optima 2000 DV (PerkinElmer). A representative sample for HRTEM (JEOL JEM-2800, $200 \mathrm{kV}$ ) analysis was prepared by dbFIB microscope (FEI Helios NanoLab 650, 2-30 kV).

\section{Electrochemical Measurements.}

Electrochemical Setup and Characterization. All electrochemical measurements were carried out in a three-electrode cell $\left(25 \pm 1{ }^{\circ} \mathrm{C}\right)$ with an AUTOLAB PGSTAT 204 potentiostat (Metrohm, Netherlands). For the synthesized GDE-Au catalysts, the working electrode was a GDE cut into an L-shape of $0.5 \times 0.5 \mathrm{~cm}^{2}$ (not taking into account the 3D structure of the GDE) and leaving adequate space on top for the electrical connection with a gold wire. The counter and reference electrodes were a slab of glassy carbon plate $\left(12.4 \mathrm{~cm}^{2}\right)$ and a mercury-mercury oxide electrode $(\mathrm{Hg}|\mathrm{HgO}| \mathrm{NaOH}, \mathrm{MOE}$, Origalys), respectively. The MOE is isolated from the solution via a Haber-Luggin bridge. However, the potentials were scaled with respect to RHE according to the scaling relation $E(\mathrm{~V}$ vs. $\mathrm{RHE})=E(\mathrm{~V}$ vs. $\mathrm{MOE})+\Delta E$ with $\Delta E=0.920$, and $0.946 \mathrm{~V}$ for 0.1 and 1.0 $\mathrm{M} \mathrm{NaOH}$, respectively. This was achieved by a steady-state $\mathrm{CV}$ recorded in the electrolyte saturated with $\mathrm{H}_{2}$ and employing Pt plate, Pt mesh, and MOE as the working, counter, and reference electrodes, respectively. Catalytic ink preparation for the commercial Vulcan-Au material was done by ultrasonically mixing MQ water $(260 \mu \mathrm{L})$, iPrOH $(100 \mu \mathrm{L})$, and Nafion ${ }^{\circledR}$ 
suspension $(40 \mu \mathrm{L})$. This was followed by the addition of $4 \mathrm{mg}$ of the commercial $\mathrm{Au} / \mathrm{C}$ catalyst and ultrasonically mixing. Finally, different volumes $(5,10$, and $20 \mu \mathrm{L})$ of the ink were deposited on each side of the above L-shape GDE and dried at ambient conditions. For the commercial $\mathrm{Au} / \mathrm{C}(19 \mathrm{wt} \%)$, those volumes correspond to the gold loadings of 38,76 , and $152 \mu \mathrm{g}_{\mathrm{Au}} \mathrm{cm}^{-2}$.

Performance towards Glucose Electrocatalysis. The glycerol $(0.1 \mathrm{M})$ electrooxidation reaction in $\mathrm{NaOH}(0.1$ and $1.0 \mathrm{M})$ was studied by $\mathrm{CV}$ and EIS. EIS was performed from $100 \mathrm{kHz}$ to 25 $\mathrm{mHz}$ at different electrodes potentials and $10 \mathrm{mV}$ amplitude. Unless otherwise stated, the voltammograms were not corrected by the "potential drop".

Underpotential Deposition of Lead $\left(P b_{U P D}\right)$. Pb $b_{U P D}$ study was performed in $0.1 \mathrm{M} \mathrm{NaOH}+1 \mathrm{mM}$ $\mathrm{Pb}\left(\mathrm{NO}_{3}\right)_{2}$ and starting the electrode potential from 800 to $250 \mathrm{mV}$ vs. RHE.

\section{ACKNOWLEDGMENT}

This work was supported by the European Institute of Membranes of Montpellier (Exploratory Project COGENFC, PAT-Energy-Axis, 2018-2019) and the Army Research Office MURI (W911NF-14-1-0263). This work made use of the University of Utah USTAR shared facilities supported, in part, by the MRSEC Program of NSF under Award No. DMR-1121252 for the characterization by S/TEM and dbFIB. We thank Didier Cot, Bertrand Rebiere, and Arie van der Lee of IEM for assistance during SEM, EDX XRD characterizations.

\section{REFERENCES}

(1) Del Castillo, A.; Alvarez-Guerra, M.; Irabien, A. Continuous electroreduction of $\mathrm{CO} 2$ to formate using Sn gas diffusion electrodes. AIChE J. 2014, 60, 3557-3564.

(2) Jhong, H.-R. M.; Brushett, F. R.; Kenis, P. J. A. The Effects of Catalyst Layer Deposition Methodology on Electrode Performance. Adv. Energy Mater. 2013, 3, 589-599.

(3) Higgins, D.; Hahn, C.; Xiang, C.; Jaramillo, T. F.; Weber, A. Z. Gas-Diffusion Electrodes for Carbon Dioxide Reduction: A New Paradigm. ACS Energy Lett. 2018, 4, 317-324.

(4) Xu, D.; Stevens, M. B.; Cosby, M. R.; Oener, S. Z.; Smith, A. M.; Enman, L. J.; Ayers, K. E.; Capuano, C. B.; Renner, J. N.; Danilovic, N.; Li, Y.; Wang, H.; Zhang, Q.; Boettcher, S. W. 
Earth-Abundant Oxygen Electrocatalysts for Alkaline Anion-Exchange-Membrane Water Electrolysis: Effects of Catalyst Conductivity and Comparison with Performance in ThreeElectrode Cells. ACS Catal. 2019, 9, 7-15.

(5) Shao, M.; Chang, Q.; Dodelet, J.-P.; Chenitz, R. Recent Advances in Electrocatalysts for Oxygen Reduction Reaction. Chem. Rev. 2016, 116, 3594-3657.

(6) Vesborg, P. C. K.; Jaramillo, T. F. Addressing the terawatt challenge: scalability in the supply of chemical elements for renewable energy. RSC $A d v$. 2012, 2, 7933-7947.

(7) Weber, M.; Tuleushova, N.; Zgheib, J.; Lamboux, C.; Iatsunskyi, I.; Coy, E.; Flaud, V.; Tingry, S.; Cornu, D.; Miele, P.; Bechelany, M.; Holade, Y. Enhanced electrocatalytic performance triggered by atomically bridged boron nitride between palladium nanoparticles and carbon fibers in gas-diffusion electrodes. Appl. Catal. B: Env. 2019, 257, 117917.

(8) Barr, M. K. S.; Assaud, L.; Brazeau, N.; Hanbücken, M.; Ntais, S.; Santinacci, L.; Baranova, E. A. Enhancement of Pd Catalytic Activity toward Ethanol Electrooxidation by Atomic Layer Deposition of SnO2 onto TiO2 Nanotubes. J. Phys. Chem. C 2017, 121, 1772717736.

(9) Yu, N.-F.; Tian, N.; Zhou, Z.-Y.; Sheng, T.; Lin, W.-F.; Ye, J.-Y.; Liu, S.; Ma, H.-B.; Sun, S.-G. Pd Nanocrystals with Continuously Tunable High-Index Facets as a Model Nanocatalyst. ACS Catal. 2019, 9, 3144-3152.

(10) Wei, L.; Mao, Y.-J.; Wei, Y.-S.; Li, J.-W.; Nie, X.-M.; Zhao, X.-S.; Fan, Y.-J.; Sun, S.G. Concentration-Mediated Shape Evolution of Palladium Nanocrystals and Their StructureElectrocatalytic Functionality. Cryst. Growth Des. 2019, 19, 1532-1539.

(11) Song, F.; Li, W.; Yang, J.; Han, G.; Yan, T.; Liu, X.; Rao, Y.; Liao, P.; Cao, Z.; Sun, Y. Interfacial Sites between Cobalt Nitride and Cobalt Act as Bifunctional Catalysts for Hydrogen Electrochemistry. ACS Energy Lett. 2019, 1594-1601.

(12) Li, M.; Wang, H.; Zhu, W.; Li, W.; Wang, C.; Lu, X. RuNi Nanoparticles Embedded in N-Doped Carbon Nanofibers as a Robust Bifunctional Catalyst for Efficient Overall Water Splitting. Advanced Science 2020, 7, Article Number: 1901833.

(13) Both Engel, A.; Bechelany, M.; Fontaine, O.; Cherifi, A.; Cornu, D.; Tingry, S. One-Pot Route to Gold Nanoparticles Embedded in Electrospun Carbon Fibers as an Efficient Catalyst Material for Hybrid Alkaline Glucose Biofuel Cells. ChemElectroChem 2016, 3, 629-637. 
(14) Yu, H.; Davydova, E. S.; Ash, U.; Miller, H. A.; Bonville, L.; Dekel, D. R.; Maric, R. Palladium-ceria nanocatalyst for hydrogen oxidation in alkaline media: Optimization of the PdCeO2 interface. Nano Energy 2019, 57, 820-826.

(15) Ayers, K. E.; Renner, J. N.; Danilovic, N.; Wang, J. X.; Zhang, Y.; Maric, R.; Yu, H. Pathways to ultra-low platinum group metal catalyst loading in proton exchange membrane electrolyzers. Catal. Today 2016, 262, 121-132.

(16) Zeng, Y.; Zhang, H.; Wang, Z.; Jia, J.; Miao, S.; Song, W.; Xiao, Y.; Yu, H.; Shao, Z.; Yi, B. Nano-engineering of a 3D-ordered membrane electrode assembly with ultrathin Pt skin on open-walled PdCo nanotube arrays for fuel cells. J. Mater. Chem. A 2018, 6, 6521-6533.

(17) Zhao, Z.; Qin, F.; Kasiraju, S.; Xie, L.; Alam, M. K.; Chen, S.; Wang, D.; Ren, Z.; Wang, Z.; Grabow, L. C.; Bao, J. Vertically Aligned MoS2/Mo2C hybrid Nanosheets Grown on Carbon Paper for Efficient Electrocatalytic Hydrogen Evolution. ACS Catal. 2017, 7, 7312-7318.

(18) Verma, S.; Lu, S.; Kenis, P. J. A. Co-electrolysis of CO2 and glycerol as a pathway to carbon chemicals with improved technoeconomics due to low electricity consumption. Nat. Energy 2019, 4, 466-474.

(19) Boukil, R.; Tuleushova, N.; Cot, D.; Rebiere, B.; Bonniol, V.; Cambedouzou, J.; Tingry, S.; Cornu, D.; Holade, Y. Enhanced electrocatalytic activity and selectivity of glycerol oxidation triggered by nanoalloyed silver-gold nanocages directly grown onto gas diffusion electrodes. $J$. Mater. Chem. A 2020, DOI: 10.1039/D1030TA01063D.

(20) González-Cobos, J.; Baranton, S.; Coutanceau, C. Development of Bismuth-Modified PtPd Nanocatalysts for the Electrochemical Reforming of Polyols into Hydrogen and ValueAdded Chemicals. ChemElectroChem 2016, 3, 1694-1704.

(21) Holade, Y.; Tuleushova, N.; Tingry, S.; Servat, K.; Napporn, T. W.; Guesmi, H.; Cornu, D.; Kokoh, K. B. Recent advances in the electrooxidation of biomass-based organic molecules for energy, chemicals and hydrogen production. Catal. Sci. Technol. 2020, 10, 3071-3112.

(22) Glüsen, A.; Dionigi, F.; Paciok, P.; Heggen, M.; Müller, M.; Gan, L.; Strasser, P.; DuninBorkowski, R. E.; Stolten, D. Dealloyed PtNi-Core-Shell Nanocatalysts Enable Significant Lowering of Pt Electrode Content in Direct Methanol Fuel Cells. ACS Catal. 2019, 9, 37643772 .

(23) Bardow, A.; Wessling, M. Converting two wastes to value. Nat. Energy 2019, 4, 440441. 
(24) Kwon, Y.; Schouten, K. J. P.; Koper, M. T. M. Mechanism of the Catalytic Oxidation of Glycerol on Polycrystalline Gold and Platinum Electrodes. ChemCatChem 2011, 3, 1176-1185.

(25) Beden, B.; Çetin, I.; Kahyaoglu, A.; Takky, D.; Lamy, C. Electrocatalytic oxidation of saturated oxygenated compounds on gold electrodes. J. Catal. 1987, 104, 37-46.

(26) Gomes, J.; Tremiliosi-Filho, G. Spectroscopic Studies of the Glycerol Electro-Oxidation on Polycrystalline Au and Pt Surfaces in Acidic and Alkaline Media. Electrocatalysis 2011, 2, 96-105.

(27) Houache, M. S. E.; Hughes, K.; Baranova, E. A. Study on catalyst selection for electrochemical valorization of glycerol. Sustainable Energy Fuels 2019, 3, 1892-1915.

(28) Xu, H.; Wang, J.; Yan, B.; Zhang, K.; Li, S.; Wang, C.; Shiraishi, Y.; Du, Y.; Yang, P. Hollow AuxAg/Au core/shell nanospheres as efficient catalysts for electrooxidation of liquid fuels. Nanoscale 2017, 9, 12996-13003.

(29) Holade, Y.; Hickey, D. P.; Minteer, S. D. Halide-regulated growth of electrocatalytic metal nanoparticles directly onto a carbon paper electrode. J. Mater. Chem. A 2016, 4, 1715417162.

(30) Li, G. G.; Lin, Y.; Wang, H. Residual Silver Remarkably Enhances Electrocatalytic Activity and Durability of Dealloyed Gold Nanosponge Particles. Nano Lett. 2016, 16, 72487253.

(31) Rizo, R.; Roldan Cuenya, B. Shape-Controlled Nanoparticles as Anodic Catalysts in Low-Temperature Fuel Cells. ACS Energy Lett. 2019, 4, 1484-1495.

(32) Arán-Ais, R. M.; Vidal-Iglesias, F. J.; Solla-Gullón, J.; Herrero, E.; Feliu, J. M. Electrochemical Characterization of Clean Shape-Controlled Pt Nanoparticles Prepared in Presence of Oleylamine/Oleic Acid. Electroanalysis 2015, 27, 945-956.

(33) Chen, G.; Tan, Y.; Wu, B.; Fu, G.; Zheng, N. Carbon monoxide-controlled synthesis of surface-clean Pt nanocubes with high electrocatalytic activity. Chem. Commun. 2012, 48, 27582760 .

(34) Usher, A.; McPhail, D. C.; Brugger, J. A spectrophotometric study of aqueous Au(III) halide-hydroxide complexes at 25-80 ${ }^{\circ} \mathrm{C}$. Geochim. Cosmochim. Acta 2009, 73, 3359-3380.

(35) Grzelczak, M.; Perez-Juste, J.; Mulvaney, P.; Liz-Marzan, L. M. Shape control in gold nanoparticle synthesis. Chem. Soc. Rev. 2008, 37, 1783-1791. 
(36) Xin, W.; Severino, J.; De Rosa, I. M.; Yu, D.; McKay, J.; Ye, P.; Yin, X.; Yang, J.-M.;

Carlson, L.; Kodambaka, S. One-Step Synthesis of Tunable-Size Gold Nanoplates on Graphene Multilayers. Nano Lett. 2018, 18, 1875-1881.

(37) Zhang, Z.; Li, H.; Zhang, F.; Wu, Y.; Guo, Z.; Zhou, L.; Li, J. Investigation of HalideInduced Aggregation of Au Nanoparticles into Spongelike Gold. Langmuir 2014, 30, 2648-2659.

(38) You, Y.-H.; Lin, Y.-W.; Chen, C.-Y. Surface-enhanced Raman scattering-active desertrose-like Ag mesoparticles prepared using cyclic voltammetric methods. $R S C A d v$. 2015, 5, 93293-93300.

(39) Fang, J.; Du, S.; Lebedkin, S.; Li, Z.; Kruk, R.; Kappes, M.; Hahn, H. Gold

Mesostructures with Tailored Surface Topography and Their Self-Assembly Arrays for SurfaceEnhanced Raman Spectroscopy. Nano Lett. 2010, 10, 5006-5013.

(40) Darienzo, R. E.; Mironava, T.; Tannenbaum, R. Raman Signal Enhancement by QuasiFractal Geometries of Au Nanoparticles. J. Nanosci. Nanotechnol. 2019, 19, 4740-4746.

(41) Watzky, M. A.; Finke, R. G. Transition Metal Nanocluster Formation Kinetic and Mechanistic Studies. A New Mechanism When Hydrogen Is the Reductant: Slow, Continuous Nucleation and Fast Autocatalytic Surface Growth. J. Am. Chem. Soc. 1997, 119, 10382-10400.

(42) Niederberger, M.; Cölfen, H. Oriented attachment and mesocrystals: Non-classical crystallization mechanisms based on nanoparticle assembly. Phys. Chem. Chem. Phys. 2006, 8, 3271-3287.

(43) Kulak, A. N.; Iddon, P.; Li, Y.; Armes, S. P.; Cölfen, H.; Paris, O.; Wilson, R. M.; Meldrum, F. C. Continuous Structural Evolution of Calcium Carbonate Particles: A Unifying Model of Copolymer-Mediated Crystallization. J. Am. Chem. Soc. 2007, 129, 3729-3736.

(44) You, H.; Yang, S.; Ding, B.; Yang, H. Synthesis of colloidal metal and metal alloy nanoparticles for electrochemical energy applications. Chem. Soc. Rev. 2013, 42, 2880-2904.

(45) Holade, Y.; Engel, A. B.; Servat, K.; Napporn, T. W.; Morais, C.; Tingry, S.; Cornu, D.; Kokoh, K. B. Electrocatalytic and Electroanalytic Investigation of Carbohydrates Oxidation on Gold-Based Nanocatalysts in Alkaline and Neutral pHs. J. Electrochem. Soc. 2018, 165, H425H436.

(46) Wang, Z.; Liu, P.; Han, J.; Cheng, C.; Ning, S.; Hirata, A.; Fujita, T.; Chen, M. Engineering the internal surfaces of three-dimensional nanoporous catalysts by surfactantmodified dealloying. Nat. Commun. 2017, 8, 1066. 
(47) Hernández, J.; Solla-Gullón, J.; Herrero, E. Gold nanoparticles synthesized in a water-inoil microemulsion: electrochemical characterization and effect of the surface structure on the oxygen reduction reaction. J. Electroanal. Chem. 2004, 574, 185-196.

(48) Hamelin, A.; Lipkowski, J. Underpotential deposition of lead on gold single crystal faces: Part II. General discussion. J. Electroanal. Chem. Interf. Electrochem. 1984, 171, $317-$ 330.

(49) Hamelin, A. Underpotential deposition of lead on single crystal faces of gold: Part I. The influence of crystallographic orientation of the substrate. J. Electroanal. Chem. Interf. Electrochem. 1984, 165, 167-180.

(50) Hebié, S.; Holade, Y.; Maximova, K.; Sentis, M.; Delaporte, P.; Kokoh, K. B.; Napporn, T. W.; Kabashin, A. V. Advanced Electrocatalysts on the Basis of Bare Au Nanomaterials for Biofuel Cell Applications. ACS Catal. 2015, 5, 6489-6496.

(51) Hebié, S.; Cornu, L.; Napporn, T. W.; Rousseau, J.; Kokoh, B. K. Insight on the Surface Structure Effect of Free Gold Nanorods on Glucose Electrooxidation. J. Phys. Chem. C 2013, $117,9872-9880$.

(52) Wang, J.; Gong, J.; Xiong, Y.; Yang, J.; Gao, Y.; Liu, Y.; Lu, X.; Tang, Z. Shapedependent electrocatalytic activity of monodispersed gold nanocrystals toward glucose oxidation. Chem. Commun. 2011, 47, 6894-6896.

(53) Chen, Z.; Liu, C.; Zhao, X.; Yan, H.; Li, J.; Lyu, P.; Du, Y.; Xi, S.; Chi, K.; Chi, X.; Xu, H.; Li, X.; Fu, W.; Leng, K.; Pennycook, S. J.; Wang, S.; Loh, K. P. Promoted Glycerol Oxidation Reaction in an Interface-Confined Hierarchically Structured Catalyst. Adv. Mater. 2019, 31, 1804763.

(54) Li, S.; Lai, J.; Luque, R.; Xu, G. Designed multimetallic Pd nanosponges with enhanced electrocatalytic activity for ethylene glycol and glycerol oxidation. Energy Environ. Sci. 2016, 9 , 3097-3102.

(55) Hong, W.; Shang, C.; Wang, J.; Wang, E. Bimetallic PdPt nanowire networks with enhanced electrocatalytic activity for ethylene glycol and glycerol oxidation. Energy Environ. Sci. 2015, 8, 2910-2915.

(56) Zhou, Y.; Shen, Y.; Xi, J. Seed-mediated synthesis of PtxAuy@Ag electrocatalysts for the selective oxidation of glycerol. Appl. Catal. B: Env. 2019, 245, 604-612. 
(57) Xu, H.; Wei, J.; Zhang, M.; Wang, C.; Shiraishi, Y.; Guo, J.; Du, Y. Solvent-mediated length tuning of ultrathin platinum-cobalt nanowires for efficient electrocatalysis. J. Mater. Chem. A 2018, 6, 24418-24424.

(58) Zalineeva, A.; Serov, A.; Padilla, M.; Martinez, U.; Artyushkova, K.; Baranton, S.; Coutanceau, C.; Atanassov, P. B. Self-Supported PdxBi Catalysts for the Electrooxidation of Glycerol in Alkaline Media. J. Am. Chem. Soc. 2014, 136, 3937-3945.

(59) Zhou, Y.; Shen, Y.; Xi, J.; Luo, X. Selective Electro-Oxidation of Glycerol to Dihydroxyacetone by PtAg Skeletons. ACS Appl. Mater. Interfaces. 2019, 11, 28953-28959.

(60) Palma, L. M.; Almeida, T. S.; Morais, C.; Napporn, T. W.; Kokoh, K. B.; de Andrade, A. R. Effect of Co-catalyst on the Selective Electrooxidation of Glycerol over Ruthenium-based Nanomaterials. ChemElectroChem 2017, 4, 39-45.

(61) Xu, D.; Liu, Y.; Zhao, S.; Lu, Y.; Han, M.; Bao, J. Novel surfactant-directed synthesis of ultra-thin palladium nanosheets as efficient electrocatalysts for glycerol oxidation. Chem. Commun. 2017, 53, 1642-1645.

(62) Holade, Y.; Morais, C.; Servat, K.; Napporn, T. W.; Kokoh, K. B. Toward the Electrochemical Valorization of Glycerol: Fourier Transform Infrared Spectroscopic and Chromatographic Studies. ACS Catal. 2013, 3, 2403-2411.

(63) Parpot, P.; Kokoh, K. B.; Beden, B.; Lamy, C. Electrocatalytic oxidation of saccharose in alkaline medium. Electrochim. Acta 1993, 38, 1679-1683.

(64) Orazem, M. E.; Tribollet, B.: Electrochemical Impedance Spectroscopy; 2 ed.; John Wiley \& Sons, Inc. : Hoboken, New Jersey, USA, 2017.

(65) Lasia, A.: Electrochemical Impedance Spectroscopy and its Applications; SpringerVerlag: New York, NY, USA, 2014.

(66) Bard, A. J.; Faulkner, L. R.: Electrochemical Methods: Fundamentals and Applications; 2nd ed.; John Wiley \& Sons, Inc.: USA, 2001.

(67) Voiry, D.; Chhowalla, M.; Gogotsi, Y.; Kotov, N. A.; Li, Y.; Penner, R. M.; Schaak, R. E.; Weiss, P. S. Best Practices for Reporting Electrocatalytic Performance of Nanomaterials. ACS Nano 2018, 12, 9635-9638.

(68) Ho, J. C. K.; Filho, G. T.; Simpraga, R.; Conway, B. E. Structure influence on electrocatalysis and adsorption of intermediates in the anodic $\mathrm{O} 2$ evolution at dimorphic $\alpha$ - and $\beta$-PbO2. J. Electroanal. Chem. 1994, 366, 147-162. 
(69) Lai, Y.; Li, Y.; Jiang, L.; Xu, W.; Lv, X.; Li, J.; Liu, Y. Electrochemical behaviors of codeposited $\mathrm{Pb} / \mathrm{Pb}-\mathrm{MnO} 2$ composite anode in sulfuric acid solution - Tafel and EIS investigations. J. Electroanal. Chem. 2012, 671, 16-23.

(70) Audichon, T.; Napporn, T. W.; Canaff, C.; Morais, C.; Comminges, C.; Kokoh, K. B. $\mathrm{IrO}_{2}$ Coated on $\mathrm{RuO}_{2}$ as Efficient and Stable Electroactive Nanocatalysts for Electrochemical Water Splitting. J. Phys. Chem. C 2016, 120, 2562-2573. 
TABLE OF CONTENTS

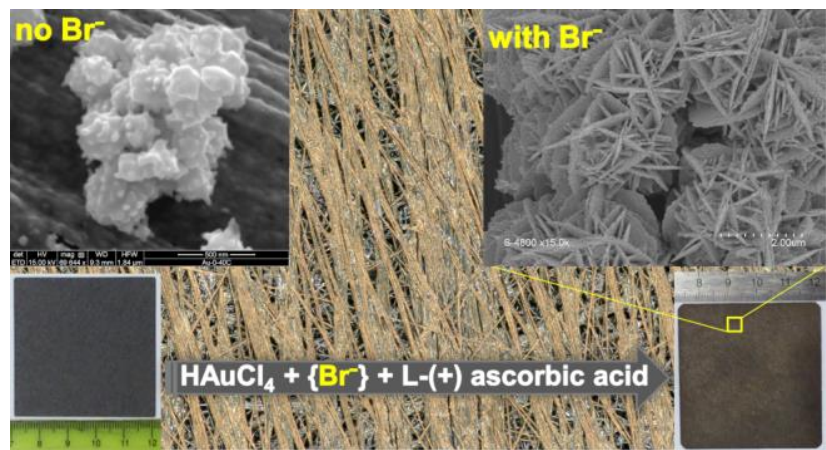

